\title{
Antimicrobial Activity of Wild Plant Seed Extracts against Human Bacterial and Plant Fungal Pathogens
}

\author{
Valentina I. Pushkareva ${ }^{1 *}$, Marina P. Slezina ${ }^{2 * \#, ~ T a t y a n a ~ V . ~ K o r o s t y l e v a ~}{ }^{2}$, \\ Larisa A. Shcherbakova ${ }^{3}$, Ekaterina A. Istomina' ${ }^{2}$, Svetlana A. Ermolaeva1, \\ Olga A. Ogarkova ${ }^{2}$, Tatyana I. Odintsova ${ }^{2}$

\begin{abstract}
${ }^{1}$ Gamaleya Research Center of Epidemiology and Microbiology, Russian Academy of Medicinal Sciences, Moscow, Russia
${ }^{2}$ Vavilov Institute of General Genetics, Russian Academy of Sciences, Moscow, Russia

${ }^{3}$ All-Russian Research Institute of Phytopathology, Russian Academy of Sciences, Bolshie Vyazemy, Russia
\end{abstract} \\ Email: "omey@list.ru
}

How to cite this paper: Pushkareva, V.I., Slezina, M.P., Korostyleva, T.V., Shcherbakova, L.A., Istomina, E.A., Ermolaeva, S.A., Ogarkova, O.A. and Odintsova, T.I. (2017) Antimicrobial Activity of Wild Plant Seed Extracts against Human Bacterial and Plant Fungal Pathogens. American Journal of Plant Sciences, 8, 1572-1592.

https://doi.org/10.4236/ajps.2017.87109

Received: April 21, 2017

Accepted: June 17, 2017

Published: June 21, 2017

Copyright $\odot 2017$ by authors and Scientific Research Publishing Inc. This work is licensed under the Creative Commons Attribution International License (CC BY 4.0).

http://creativecommons.org/licenses/by/4.0/

\begin{abstract}
Five wild plant species belonging to different families (Chenopodium album, Plantago major, Elytrigia elongata, Filipendula ulmaria and Nigella sativa) widely spread in Russian Federation and the former USSR were evaluated for their ability to inhibit growth of two important human food-borne pathogens (Escherichia coli O157:H7 and Listeria monocytogenes strain EGD-e) and eight plant pathogens (Alternaria alternata, Alternaria tenuissima, Bipolaris sorokiniana, Stagonospora nodorum, Fusarium solani, Fusarium oxysporum, Fusarium culmorum and Phytophtora infestans). To isolate biologically active compounds from seeds, a step-wise procedure including extraction with hexane, ethyl acetate, ethanol, and $10 \%$ acetic acid followed by reversed-phase HPLC was developed. Using disc-diffusion assay, the highest activity against E. coli $\mathrm{O} 157: \mathrm{H} 7$ was observed with extracts from $F$. ulmaria (hexane and ethyl acetate extracts and the unbound RP-HPLC fraction) and $P$. major (ethyl acetate extract and the unbound RP-HPLC fraction); E. elongata (the unbound RP-HPLC fraction) was less active. The extracts from $P$. major and E. elongata (the unbound RP-HPLC fractions) were equally highly active against L. monocytogenes, while those of F. ulmaria (the unbound RP-HPLC fraction) and $N$. sativa (hexane and ethyl acetate extracts) were less active against this pathogen. The dynamics of L. monocytogenes EGD-e and E. coli O157:H7 growth in the presence of two most potent extracts (RP-HPLC-unbound fractions of $P$. major and E. elongata and the hexane extract of $F$. ulmaria) was studied. All plant extracts caused considerable reduction of the bacterial population already after $24 \mathrm{~h}$ of incubation. Antifungal assays showed that the
\end{abstract}

*The first two authors contributed equally to this work. 
ethanol extract and both RP-HPLC fractions of $F$. ulmaria completely inhibited spore germination in all tested fungi. The RP-HPLC-bound fraction from $N$. sativa completely inhibited spore germination in $P$. infestans and $B$. sorokiniana. Both RP-HPLC fractions of the plants examined (except for $C$. album) completely inhibited spore germination in $S$. nodorum. Significant inhibition of F. culmorum spore germination was recorded with both RP-HPLC fractions from E. elongata and RP-HPLC unbound fraction of $P$. major. $F$. oxysporum spore germination was also inhibited by the RP-HPLC bound fraction of $C$. album. B. sorokiniana and A. alternata appeared to be less sensitive to plant extracts. The results obtained expand the repertoire of valuable biological activities discovered in plants for future use in medicine, food preservation and crop protection.

\section{Keywords}

Plant Extracts, Antibacterial Activity, Human Food-Borne Pathogens, Antifungal Activity, Plant Pathogenic Fungi

\section{Introduction}

Despite enormous progress in medicine, infectious diseases pose a serious threat to human health. Intestinal infections caused by pathogenic bacteria occupy a prominent place among them, with nearly 1.7 billion cases of diarrheal diseases registered worldwide annually [1].

Listeriosis is a dangerous human disease caused by the pathogenic bacterium Listeria monocytogenes [2] [3]. Listeriosis ranks third in the total number of deaths among food-borne pathogens with overall mortality rate of $20 \%-30 \%$ [4]. Contaminated food is usually the primary source of infection that mainly occurs through dairy products and meat [5]. However, raw vegetables can also serve as the source of infection.

L. monocytogenes is a Gram-positive, non spore-forming, facultatively anaerobic, rod-shaped bacterium which belongs to the most virulent food-borne pathogens [4]. It is widely spread in soil, water, plants, silage, sewage, milk. It was isolated from cattle, sheep, goats, poultry, hydrobionts, pets, and wild animals [4]. Vegetables appear to be often contaminated with $L$. monocytogenes, where the bacterium forms biofilms [6]. The bacterium can grow and multiply at low positive temperatures and is tolerant to freezing, drying and other stressful abiotic factors. The ability to grow at low temperatures permits the bacterium to multiply even in refrigerated foods.

L. monocytogenes possesses a limited repertoire of pathogenicity factors (seven proteins) [4]. The hemolysin designated listeriolysin $\mathrm{O}$ encoded by the hly gene is considered the major virulence factor. The listeriolysin produces large transmembrane pores which are supposed to be responsible for its cytolytic properties and destruction of erythrocytes. Human listeriosis may be caused by all 13 serovars of L. monocytogenes, however, serovars $1 / 2 \mathrm{a}, 1 / 2 \mathrm{~b}$ and $4 \mathrm{~b}$ cause 
most of the cases.

Escherichioses caused by pathogenic Escherichia coli strains represent another threat to human health. The outbreaks of diseases caused by pathogenic E. coli strains are being constantly reported in Europe, North America ( 1 - 2 cases per 100,000), and Argentina (up to 22 cases per 100,000) [1]. After dramatic epidemic of escherichiosis in Japan (more than 10000 cases) caused by consumption of radish seedlings contaminated with the enterohemorrhagic Escherichia coli O157:H7 [7], more than 40 outbreaks of the disease were registered worldwide.

E. coli is a Gram-negative, non spore-forming, facultatively anaerobic, rodshaped bacterium belonging to the family Enterobacteriaceae. It inhabits human gastrointestinal tract, however, some serovars are human pathogens that cause different disorders, such as urinary tract infections and gastrointestinal diseases [8] [9]. It has been established that the main reservoir of different serovars of enteropathogenic E. coli are farm animals (ruminants). The bacteria inhabit their gut not producing any harm to adult animals. Escherichiosis caused by enteropathogenic E. coli, which produces Shiga toxins / verotoxins (more than 100 serotypes) capable of killing Vero cells, are particularly life-threatening [10]. The genes responsible for toxin production are located in the locus of enterocyte effacement (LEE) pathogenicity island [11]. The toxins encoded by locus LEE can directly damage renal and endothelial cells. Shiga toxins I and II (Stx1 and Stx2) are responsible for the clinical manifestation of infection-hemorrhagic colitis or hemolytic uremic syndrome.

To treat infectious diseases caused by food-borne pathogenic bacteria, antibiotics have been extensively used. However, nowadays the resistance of pathogens to antibiotics is rising. The antibiotic-resistance problem stimulates the search for novel highly efficient antimicrobials. To prevent contamination of food products with pathogens causing gastrointestinal disorders, chemical preservatives are commonly used, however, they may affect human health and promote the emergence of resistant strains of pathogens, therefore, efforts are aimed at the development of effective and safe natural food preservatives.

Plant diseases caused by pathogenic fungi result in considerable yield losses in cultivated crops [12]. Furthermore, they decrease the quality of agricultural products. Thus, mycotoxins produced by Fusarium species and present in contaminated grain are toxic to humans and livestock; aflatoxins produced by $A s$ pergillus species are carcinogenic. Alternaria alternata (Fr.) Keissl causes diseases in over 380 host plant species. The symptoms of the disease vary from leaf spots to rots and blights. It can also cause upper respiratory tract infections and asthma in immunocompromised individuals. Alternaria tenuissima Samuel Paul Wiltshire is a cosmopolitan species and an opportunistic pathogen of plants. It often colonizes blueberries, strawberries, tomatoes, grapevine, and cereal species. It can cause skin infections in immunocompromised individuals. Bipolaris sorokiniana (Sacc.), Shoemaker is the causal agent of a wide variety of cereal diseases. The pathogen can induce disease on roots, leaves, stems and heads. Two most 
common diseases are common root rot and spot blotch on wheat and barley. Stagonospora nodorum (Berk.) Castellani \& E. G. Germane is a devasting pathogen of wheat and related cereals, causing leaf and glume blotch. The genus Fusarium comprises a wide and heterogeneous group of fungi. The host range of pathogenic strains of Fusarium oxysporum Schitdl. is exceedingly broad, and includes animals as well as plants. However, individual isolates usually cause disease only on a narrow range of plant species. On many plant species F. oxysporum causes vascular wilt followed by growth stunting, wilting, defoliation and, finally, death of the plant. Some strains are not primarily vascular pathogens, but cause foot and root rot. Fusarium culmorum (W.G.Sm.) Sacc. is the causal agent of seedling blight, foot rot, ear blight, stalk rot, common root rot and other diseases of cereals, and many other monocots and dicots. Fusarium solani (Mart.) Sacc. also causes severe crop diseases, such as root and fruit rot of Cucurbita spp., root and stem rot of pea, sudden death syndrome of soybean, foot rot of bean and dry rot of potato. Phytophthora infestans (Mont.) de Bary is an oomycete that causes the serious disease of potatoes known as late blight or potato blight. The pathogen can also infect other members of the Solanaceae family, such as tomato.

To control fungal diseases, fungicides are currently widely used. Although they reduce yield losses, they contaminate the environment with hazardous substances threatening human health. Ecologically friendly strategies to combat plant diseases are therefore necessary.

Plants extracts serve as a valuable and unique source of various biologically active compounds that can be used for different purposes: (i) to develop novel pharmaceuticals as an alternative or supplement to conventional antibiotics to treat human diseases and preserve food products from infection; (ii) to elaborate novel plant disease control formulations.

Chenopodium album L. (family Amaranthaceae) is a weed widely spread throughout Europe [13]. It is an edible plant. The leaves can be used as a leaf vegetable. Seeds are rich in starch and protein. In India, it is widely grown as a grain crop. In traditional medicine it is used to cure inflammation, cough, bronchitis, digestive tract diseases and relief pain [14]. Plantago major L. (family Plantaginaceae) is a perennial common weed native to Europe and northern and central Asia. In Russia, it is found everywhere except the Far North, the Pamirs and deserts. It often grows in lawns and fields and along roadsides. The plant is edible and rich in vitamin B1 and riboflavin. It possesses a wide range of activities, such as anti-inflammatory, antiseptic, antibacterial, cardiac, and diuretic. It quickly stops blood flow and stimulates wound healing. It is used in the treatment of diarrhea, dysentery, gastritis, bronchitis, haemorrhage, cough, and asthma [15]. Elytrigia elongata (Host) Nevski (family Poaceae) is a perennial herbaceous forage plant. It grows in Eastern Europe, Crimea, south of Russia, Caucasus, Mediterranean region, and Iran on solonchak steppe, chalk outcrops, and along seashores. Rhizomes are edible. The nutritional value of flour made of E. elongata rhizomes is similar to that of wheat. Although the medicinal proper- 
ties of this species are poorly studied, it is closely related to the weed Elytrigia repens (L.) Gould, which is used in traditional medicine as an antifungal and antibacterial agent to treat arthritis, bronchitis, skin diseases, urinary tract infections, upper respiratory tract, and liver diseases [13]. Filipendula ulmaria (L.) Maxim. (family Rosaceae) is a perennial herb growing in damp areas. It is found in most of Europe and Western Asia. It is a medicinal plant widely used for treatment of different disorders. The leaves and flowering stems are anti-inflammatory, antiseptic, diuretic and tonic. The herb is used in traditional medicine as a remedy for acidic stomach, diarrhea, rheumatism, bronchitis, cough, fever and cold. It is also a natural remedy for relieving headaches [16]. Nigella sativa L. (family Ranunculaceae) is native to Southern Europe, North Africa and Southwest Asia. Seeds have been used for centuries to treat diseases. The biological activities of $N$. sativa include immunomodulatory, antidiabetic, anticancer, analgesic, antimicrobial, asmolytic, anti-inflammatory, antioxidant, gastroprotective, hepatoprotective and many others. The seeds are used to cure many diseases, such as bronchitis, asthma, diarrhea, rheumatism, and skin disorders [17].

The aim of this study was to examine the antibacterial activity of above-described medicinal plant extracts against human bacterial pathogens $L$. monocytogenes and E. coli and their antifungal activity against important plant pathogens in order to evaluate their potential for therapeutic use in healthcare and food preservation and as natural antibiotics for protection of plants against diseases.

\section{Materials and Methods}

\subsection{Plant Materials and Microorganisms}

Seeds of C. album, P. major, E. elongata and F. ulmaria were collected in 2012 in Moscow region. Seeds of $N$. sativa were collected in Zangiatinskii region of Uzbekistan in 2012 .

The microorganisms used in this study were as follows: L. monocytogenes strain EGD-e obtained from Prof. J.A. Vazquez-Boland (Department of Molecular Microbiology, University of Bristol, UK), toxin-producing strain of E. coli (VT1) (O157:H7) ATCC 43890 (USA). Isolates of $A$. alternata, A. tenuissima, $B$. sorokiniana, $S$. nodorum, F. solani, $P$. infestans were obtained from the Collection of Phytopathogenic Microorganisms of the All-Russian Research Institute of Phytopathology; F. oxysporum strain VKM-137 and F. culmorum strain VKM-2303 were received from the All-Russian Collection of Microorganisms of the G.P. Skryabin Institute of Biochemistry and Physiology of Microorganisms RAS.

\subsection{Preparation of Plant Extracts}

Seeds $(3 \mathrm{~g})$ were ground into powder in a coffee mill and successively extracted with hexane (Khimmed, Russia), ethyl acetate (Khimmed, Russia), ethanol (Ferein, Russia), and $10 \%$ acetic acid (Khimmed, Russia) at a plant/solvent ratio of $1: 8(\mathrm{w} / \mathrm{v})$ under constant stirring at $30 \mathrm{rpm}$ at room temperature for $1 \mathrm{~h}$. After 
each extraction step the homogenate was centrifuged at $10,000 \mathrm{~g}$ at $4^{\circ} \mathrm{C}$ for 10 min, the pellet was discarded, and the supernatant was filtered through Whatman no.1 filter paper. The extracts obtained with acetic acid were further desalted by reversed-phase HPLC on a NewGuard C18 column (3.2x15 mm) (Applied Biosystems, USA). Elution with $0.1 \%$ trifluoroacetic acid (TFA) (Fluka, Switzerland) yielded the unbound fraction, while the bound fraction was recovered with 50\% acetonitrile (Panreac, Spain) in 0.1\% TFA. All extracts and both RP-HPLC fractions (bound and unbound) were evaporated on a rotary evaporator (Savant, USA), lyophilized, stored at $-80^{\circ} \mathrm{C}$, and dissolved immediately before use in $1 \mathrm{ml}$ of $5 \%$ dimethyl sulfoxide (DMSO) (Amresco, USA).

\subsection{Antibacterial Assays}

L. monocytogenes and E. coli were cultured on liquid and solid BHI (Difco, USA) media at $37^{\circ} \mathrm{C}$ for $24 \mathrm{~h}$. Inhibition of bacterial growth was assayed by the disc diffusion method developed for commercial antibiotics [18]. Broth cultures adjusted to a concentration of $10^{6}$ colony forming units (CFU) per ml were streaked on Mueller-Hinton Agar in Petri dishes (Himedia, India). Filter paper discs were impregnated with 25,50 and $75 \mu$ of plant extracts and placed on the inoculated surface of the agar plates. The plates were incubated at $37^{\circ} \mathrm{C}$ for $24 \mathrm{~h}$, whereupon the diameters (in $\mathrm{mm}$ ) of zones of microbial inhibition produced by plant extracts were measured. Pure 5\% DMSO was used as control.

The survival of the bacteria in the presence of the most active plant extracts was determined by time-kill analysis (survival curve plot), in which the number of viable bacterial cells remaining after the addition of plant extracts was plotted against time. For this assay, agar plates were inoculated with stock solutions of plant extracts mixed with bacterial suspensions at a 1:10 (v/v) ratio. The number of viable cells was calculated after incubation for $2 \mathrm{~h}, 1,2,3,4$ and 5 days and expressed in $\mathrm{CFU} / \mathrm{ml}$.

\subsection{Antifungal Assays}

For antifungal assays spores were washed from the surface of fungal colonies grown on potato-dextrose agar at $25^{\circ} \mathrm{C}$ for 14 days (A. alternata, A. tennuissima, B. sorokiniana, S. nodorum, F. solani, F. oxysporum, F. culmorum) or on oats agar at $21^{\circ} \mathrm{C}-22^{\circ} \mathrm{C}(P$. infestans). Spores were separated from mycelium fragments by filtration through the cotton and nylon filters, sedimented by centrifugation at $3000 \mathrm{~g}$ for $20 \mathrm{~min}$ and resuspended in the minimum volume of distilled water.

Fungitoxicity of plant extracts from F. ulmaria and $N$. sativa was assayed by microscopic examination of spore germination in the presence of plant extracts. Plant extracts were diluted 1:10 (v/v) with spore suspensions of $A$. tenuissima, $B$. sorokiniana, F. solani and P. infestans at a concentration of $2 \times 10^{5} / \mathrm{ml}$ (the RP-HPLC-bound fraction of $F$. ulmaria was additionally diluted 1:10 and 1:50 $(\mathrm{v} / \mathrm{v})$ ) on slide plates (four slides per variant). Then the slide plates were placed into humid chamber and incubated at $22^{\circ} \mathrm{C}$ in the dark for $24 \mathrm{~h}$. Spore suspen- 
sions in 5\% DMSO were used as controls. The effect of plant extracts on spore germination was evaluated at two time points, after $5-6 \mathrm{~h}$ and $24 \mathrm{~h}$.

To test antifungal activity of extracts from C. album, P. major and E. elongata, the assay based on germination of spores in thin agar layers was used. Equal volumes of spore suspensions and plant extracts were mixed to yield the final spore concentration of $10^{4} / \mathrm{ml}$ for A. alternata, B. sorokiniana, $F$. oxysporum, and $F$. culmorum and $3 \times 10^{3} / \mathrm{ml}$ for $S$. nodorum. Suspensions were incubated at room temperature for $25-30 \mathrm{~min}$ at constant gentle stirring, and then $200 \mu \mathrm{l}$ of the suspension were loaded onto the slide plates covered with $1 \%$ agar ( 3 glass plates for each variant) and placed in a humid chamber. Spores of $S$. nodorum were germinated in the dark at $22^{\circ} \mathrm{C}$ for $16-18$, and for $5-6 \mathrm{~h}$ for A. alternata, $B$. sorokiniana, F. oxysporum, and F. culmorum. Suspension of spores in 5\% DMSO was used as control. Inhibition of germination induced by plant extracts was monitored under the microscope. Not less than 600 spores were examined in each experimental and control variants. Germination frequency was expressed in per cents from the number of germinated seeds in control.

All antimicrobial assays were conducted in triplicate. Statistical processing of the experimental data was carried out with the STATISTICA 6.0 program ("SoftStat Inc.", USA). The significance of differences at $p \leq 0.05$ was calculated using the $t$-test.

\section{Results}

\subsection{Antibacterial Activity of Plant Extracts against L. monocytogenes and E. coli}

Extracts from seeds of five medicinal plants growing in Moscow region and Uzbekistan were obtained and evaluated for their ability to inhibit growth of important human and plant pathogens. Seeds were successively extracted with different solvents-hexane, ethyl acetate, ethanol, and 10\% acetic acid followed by RP-HPLC of the acidic acid extract that produced two fractions-the unbound and bound to the reversed phase. The effect of 24 resulting extracts on growth of Gram+ bacterium L. monocytogenes EGD-e and Gram- bacterium E. coli O157:H7 was evaluated by disc diffusion assay. The data on $E$. coli growth inhibition are shown in Table 1. Mean values of three independent experiments are presented.

Table 1. Inhibitory activity of plant extracts against E. coli O157:H7 (inhibition zone diameter, $\mathrm{mm}$ ).

\begin{tabular}{cccccc}
\hline \multirow{2}{*}{ Plant Species } & \multicolumn{2}{c}{$10 \%$ Acetic Acid } & Hexan & $\begin{array}{c}\text { Ethyl } \\
\text { Acetate }\end{array}$ & Ethanol \\
\cline { 2 - 5 } & RP-HPLC-bound & RP-HPLC-unbound & & $<$ & $<6$ \\
\hline C. album & 0 & 0 & $<10$ & $22 \pm 2$ & 0 \\
P. major & 0 & $20 \pm 4$ & 0 & 0 & 0 \\
E. elongata & 0 & $18 \pm 3$ & $22 \pm 1$ & $20 \pm 2$ & 0 \\
F. ulmaria & 0 & $22 \pm 2$ & 0 & 0 & 0 \\
N. sativa & 0 & 0 & & & \\
\hline
\end{tabular}


Taken as control 5\% DMSO had no effect on growth of the pathogen (data not shown). The ethanol extracts and the RP-HPLC-bound fractions of all plants studied were inactive against the pathogenic E. coli strain O157:H7. The pathogen was not sensitive to the components present in $N$. sativa extracts and was weakly sensitive to the compounds found in $C$. album extracts. On the contrary, the components present in ethyl acetate, hexane, and RP-HPLC-unbound fractions of $F$. ulmaria and $P$. major displayed strong antibacterial activity against $E$. coli O157:H7. The inhibition zone was $20-22 \mathrm{~mm}$, except for the hexane extract of $P$. major where it did not exceed $10 \mathrm{~mm}$. In $E$. elongata the active against $E$. coli components were in the unbound RP-HPLC fraction of the acetic acid extract (inhibition zone of $18 \pm 3 \mathrm{~mm}$ ).

The results of antibacterial assays of the plant extracts against the virulent strain of L. monocytogenes EGD-e are presented in Table 2. 5\% DMSO used as control did not inhibit growth of the bacterium (data not shown). The RPHPLC-bound fractions of the acetic acid extract and the ethanol extracts of all plants studied were inactive against $L$. monocytogenes EGD-e. Conversely, the unbound RP-HPLC fractions of the acetic acid extracts of $P$. major and $E$. elongata displayed the strongest antibacterial activity, with the inhibition zone of $22 \mathrm{~mm}$. The hexane and ethyl acetate extracts of $N$. sativa, as well as the unbound fraction of the acetic acid extract of $F$. ulmaria were less active (inhibition zone of $16 \mathrm{~mm}$ ). In C. album, only the components extracted with ethyl acetate caused weak inhibition of $L$. monocytogenes (inhibition zone of $8 \mathrm{~mm}$ ). It should be noted that growth inhibition in both bacterial pathogens was observed only when $75 \mu \mathrm{l}$ of plant extract solutions were loaded onto the discs. Two-fold dilution considerably reduced the diameter of inhibition zones for both pathogens (data not shown).

Thus, of the plant species studied, only extracts from $C$. album were virtually inactive against two human pathogens. Extracts from $N$. sativa inhibited only $L$. monocytogenes. The highest activity against $E$. coli $\mathrm{O} 157: \mathrm{H} 7$ was observed with extracts from F. ulmaria (hexane and ethyl acetate extracts and the unbound RP-HPLC fraction) and $P$. major (ethyl acetate extract and the unbound RP-HPLC fraction); E. elongata (the unbound RP-HPLC fraction) was less active. The extracts from $P$. major and E. elongata (the unbound RP-HPLC frac-

Table 2. Inhibitory activity of plant extracts against L. monocytogenes EGD-e (inhibition zone diameter, $\mathrm{mm}$ )

\begin{tabular}{cccccc}
\hline \multirow{2}{*}{ Plant Species } & \multicolumn{2}{c}{$10 \%$ Acetic Acid } & Hexan & $\begin{array}{c}\text { Ethyl } \\
\text { Acetate }\end{array}$ & Ethanol \\
\cline { 2 - 5 } & RP-HPLC-bound & RP-HPLC-unbound & & 0 & $<8$ \\
\hline C. album & 0 & 0 & 0 & 0 & 0 \\
P. major & 0 & $22 \pm 2$ & 0 & 0 & 0 \\
E. elongata & 0 & $22 \pm 1$ & 0 & 0 & 0 \\
F. ulmaria & 0 & $16 \pm 1$ & $16 \pm 2$ & $16 \pm 1$ & 0 \\
N. sativa & 0 & 0 & & & \\
\hline
\end{tabular}


tions) were equally highly active against $L$. monocytogenes, while those of $F$. ulmaria (the unbound RP-HPLC fraction) and $N$. sativa (hexane and ethyl acetate extracts) were less active against this pathogen.

The dynamics of $L$. monocytogenes EGD-e and E. coli O157:H7 growth in the presence of two most potent extracts (RP-HPLC-unbound fractions of $P$. major and E. elongata and the hexane extract of $F$. ulmaria) was studied (Figure 1). The abundance of bacterial populations was measured at several time points: $2 \mathrm{~h}$, $1,2,3,4$ and 5 days after the addition of plant extracts. Changes in the number of viable E. coli cells are shown in Figure 1(a). In control (water), the number of $E$. coli cells gradually decreased by the fourth day of incubation. This tendency is characteristic of the bacteria growing on "poor" media. Both plant extracts caused considerable reduction of the bacterial population already after $24 \mathrm{~h}$ of incubation, the hexane extract of $F$. ulmaria being more effective. The effect was much more pronounced following $48 \mathrm{~h}$ of incubation with the extracts. Similar population dynamics was observed with $L$. monocytogenes in the presence of RP-HPLC-unbound fractions from P. major and E. elongata (Figure 1(b)). Cultivation of the bacteria with these extracts caused slower reduction in population abundance in comparison to E. coli followed by complete elimination of the bacteria by $96 \mathrm{~h}$. The delayed effect of plant extracts on L. monocytogenes is likely to be associated with more complex structure of cell walls in Gram+ bacteria (multilayered structured peptidoglycan) that prevents rapid diffusion of plant components into bacterial cells.

\subsection{Antifungal Activity of Plant Extracts}

To test the antifungal activity of $F$. ulmaria and $N$. sativa seed extracts, germination of fungal spores in the presence of the extracts was monitored under the microscope at two time points: after $5-6 \mathrm{~h}$ and $24 \mathrm{~h}$ of incubation.

The experiments showed that the RP-HPLC-bound fraction of the acetic acid soluble extract from $F$. ulmaria was highly active against all tested fungi $(F$. sola$n i$, A. tenuissima, B. sorokiniana) and the oomycete ( $P$. infestans) (Figure 2). Strong inhibitory effect on spore germination persisted after $24 \mathrm{~h}$ of incuba-

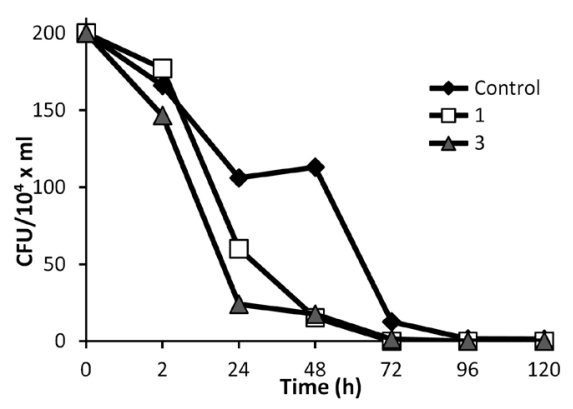

(a)

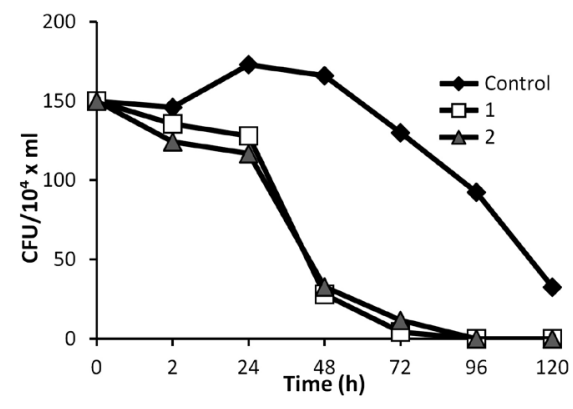

(b)

Figure 1. E. coli O157:H7 (a) and L. monocytogenes EGD-e (b) population dynamics in the presence of plant extracts: RP-HPLC unbound fractions of $P$. major (1) and E. elongata (2) acetic acid extracts, F. ulmaria hexane extract (3). 


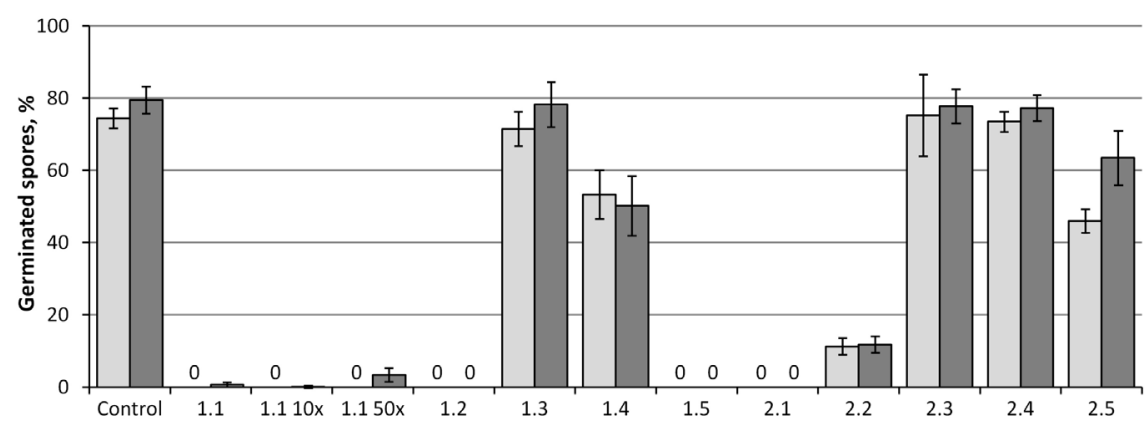

(a)

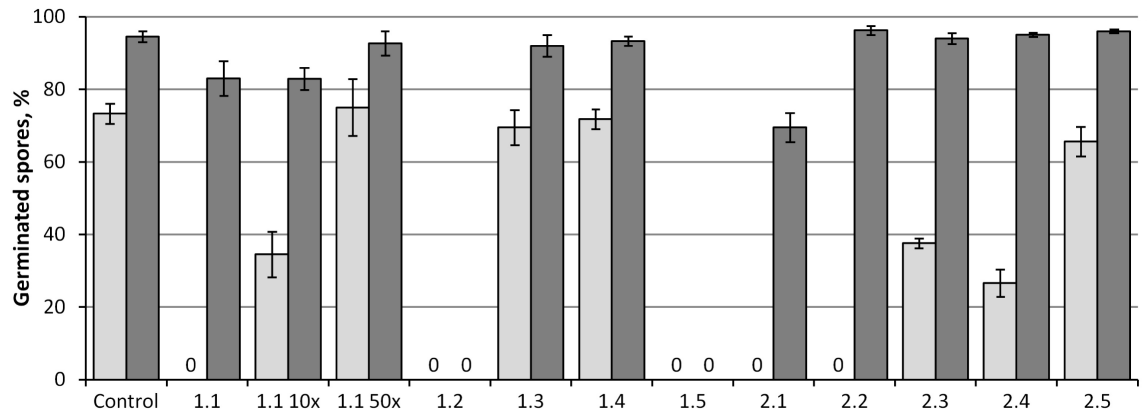

(b)

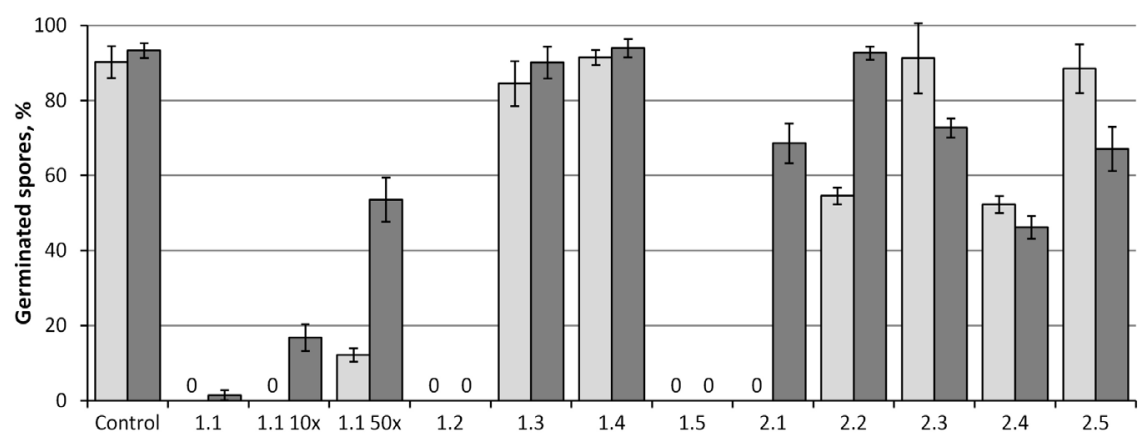

(c)

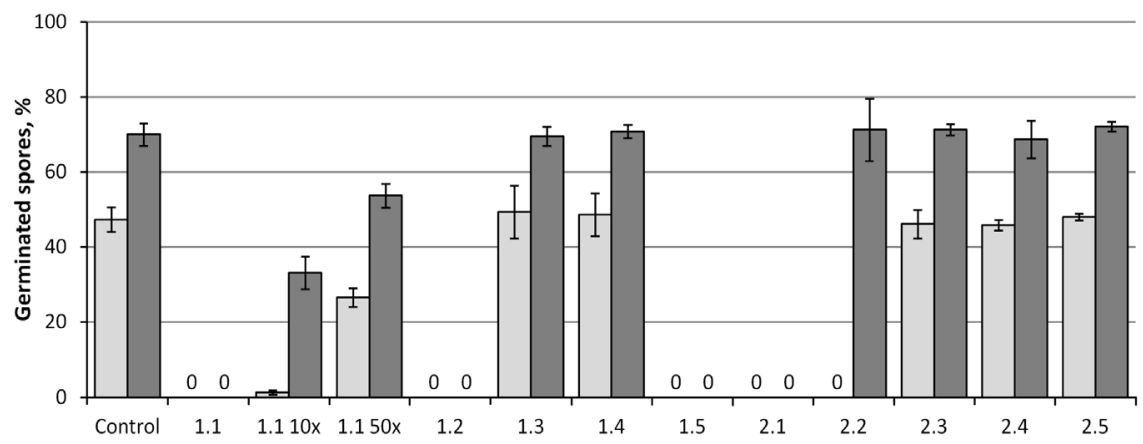

(d)

Figure 2. Germination of spores of P. infestans (a); F. solani (b); A. tenuissima (c); and $B$. sorokiniana (d) in the presence of seed extracts from F. ulmaria (1) and N. sativa (2): RP-HPLC-bound fraction of the acetic acid extract (X.1, diluted 1:10 and 1:50), RP-HPLC-unbound fraction (X.2), hexane extract (X.3), ethyl acetate extract (X.4), and ethanol extract (X.5) (for experimental details, see Materials and Methods). Grey, incubation with extracts for 5 - $6 \mathrm{~h}$, dark grey, for $24 \mathrm{~h}$. Extracts were dissolved in 5\% DMSO used as control. Standard deviations are shown. 
tion with all fungi, except for $F$. solani. Incubation of the RP-HPLC-bound fraction of the acetic acid soluble extract from $F$. ulmaria with $F$. solani spores caused $100 \%$ inhibition of spore germination after $5-6 \mathrm{~h}$ of observation, however, after $24 \mathrm{~h}$ of incubation, inhibition decreased to $11.4 \%$. Despite this fact, we discovered that F. ulmaria extract influenced the rate of hyphal elongation, which was considerably reduced: after $24 \mathrm{~h}$, the length of hypha in the presence of the extract was only $91-110 \mu$, while in the control their length reached 650 $975 \mu$. Thus, inhibition of $F$. solani was manifested by suppression of hyphal elongation. The RP-HPLC-bound fraction of the acetic acid extract from F. ulmaria virtually completely inhibited (98\%) spore germination in A. tenuissima, and in $B$. sorokiniana it was completely suppressed. Incubation of fungal spores in the presence of RP-HPLC-unbound fraction of the acetic acid extract from $F$. ulmaria and the ethanol extract from this species completely inhibited germination of spores in all tested fungi both after $5-6 \mathrm{~h}$ and $24 \mathrm{~h}$ of incubation. The hexane extract did not inhibit germination of spores of the fungi tested, while the ethyl acetate extract caused $36.7 \%$ inhibition of spore germination only in $P$. infestans.

Of $N$. sativa extracts, the acetic-acid-soluble fraction showed the highest inhibitory activity on spore germination (Figure 2). The RP-HPLC-bound fraction completely inhibited spore germination in all fungi tested. However, the effect persisted after $24 \mathrm{~h}$ only with $P$. infestans and B. sorokiniana. In F. solani, incubation with the extract for $24 \mathrm{~h}$ resulted in $26 \%$ inhibition of spore germination, however, considerable retardation of hyphal growth to $54.3-81.5 \mu$ as compared to control, was noted. The inhibitory activity of the RP-HPLC-unbound fraction was weaker on spore germination of $A$. tenuissima and $P$. infestans, and except for $P$. infestans disappeared after prolonged incubation. The hexane and ethyl acetate extracts of $N$. sativa weakly inhibited spore germination in $F$. solani and $A$. tenuissima. It is worth noting that the inhibitory effect disappeared after prolonged incubation (24 h) with $F$. solani spores. In A. tenuissima, on the contrary, the hexane extract inhibited growth $(22.1 \%)$ only after prolonged incubation with the spores. With the ethyl acetate extract, inhibition of spore germination was similar both after 5-6 and $24 \mathrm{~h}$ of incubation. The ethanol extract of $N$. sati$v a$, in addition to the above-mentioned fungi, displayed moderate activity against $P$. infestans.

In summary, the hexane and ethyl acetate extracts from $F$. ulmaria showed no inhibition of spore germination in the fungi examined, however the ethyl acetate extract was moderately active against $P$. infestans. Conversely, the ethanol extract and both RP-HPLC-bound and unbound acetic acid soluble fractions completely inhibited spore germination in all tested fungi and the oomycete (Figure 2 ). The most convincing results were obtained with the RP-HPLC-bound fraction of the acetic acid extract of $F$. ulmaria when tested against $P$. infestans. Even 50 -fold dilution of the extract caused $95.7 \%$ inhibition of spore germination in the oomycete after $24 \mathrm{~h}$ of incubation (Figure 2(a)). The extracts from $N$. sativa seeds, except for the RP-HPLC-bound fraction of the acetic acid extract, were 
less potent against the fungi studied in comparison to $F$. ulmaria. The RPHPLC-bound acetic-acid-soluble fraction was the most active: it completely inhibited spore germination in $P$. infestans and $B$. sorokiniana after $24 \mathrm{~h}$ of incubation (Figure 2(a) and Figure 2(d)). Other N. sativa extracts showed low inhibitory activity, in some cases, the effect decreased with time depending on the fungus. It should be specifically noted that although acetic-acid-soluble fractions of F. ulmaria and $N$. sativa caused weak inhibition of spore germination in $F$. solani, the rate of hyphal elongation was significantly affected.

The results of antifungal assays with RP-HPLC-bound and -unbound fractions of the acetic-acid extracts from $C$. album, $P$. major, and E. elongata against fungal pathogens are shown in Figure 3. As seen from this Figure, the acidsoluble plant extracts differ considerably in their ability to inhibit spore germination in pathogenic fungi.

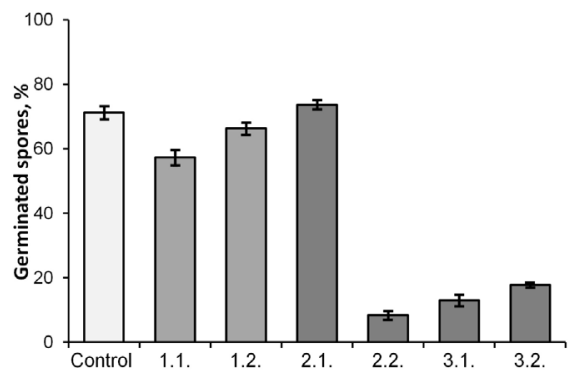

(a)

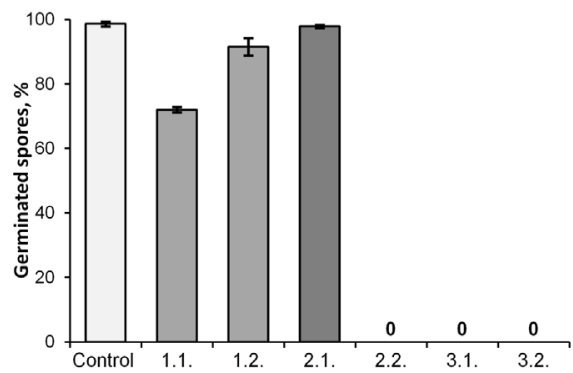

(c)

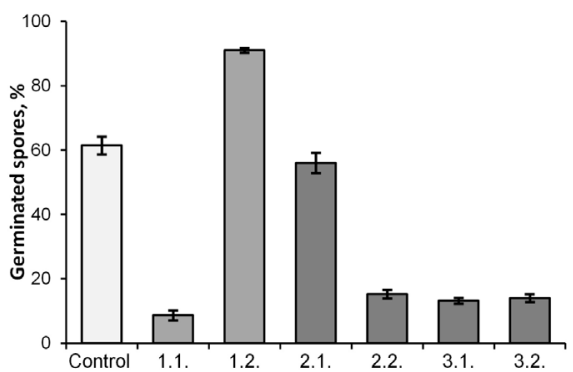

(b)

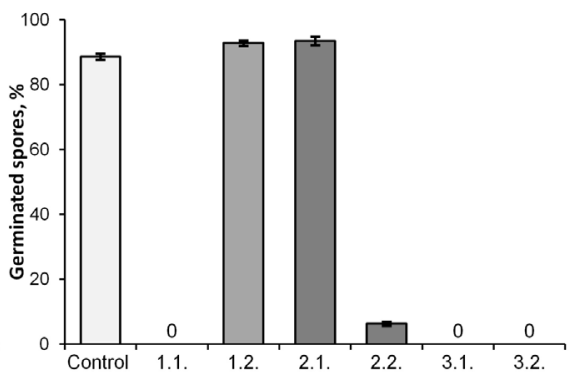

(d)

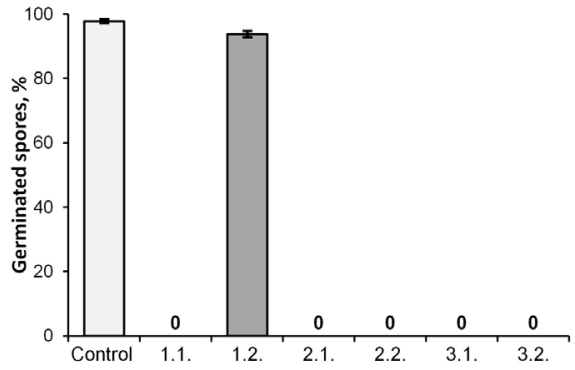

(e)

Figure 3. Germination of spores of A. alternata (a); B. sorokiniana (b); F. culmorum (c); F. oxysporum (d); and $S$. nodorum (e) in the presence of seed extracts from C. album (1), P. major (2) and E. elongata (3): RP-HPLC-bound fraction (X.1), RP-HPLC-unbound fraction (X.2) (for experimental details, see Materials and Methods). Incubation with extracts for 5 - $6 \mathrm{~h}$. Extracts were dissolved in 5\% DMSO used as control. Standard deviations are shown. 
The RP-HPLC-bound fraction of $C$. album was active against all five fungi, while the unbound fraction was inactive. A. alternata was the least sensitive fungus to this fraction (Figure 3(a)). Conversely, it was highly active against $B$. sorokiniana (Figure 3(b)), while the germination of spores in F. oxysporum and S. nodorum was completely inhibited (Figure 3(d) and Figure 3(e)). Inhibition of $F$. culmorum spore germination was moderate - 27\% (Figure 3(c)). However, similarly to the effect of the RP-HPLC-bound fractions from $F$. ulmaria and $N$. sativa seeds on $F$. solani, the extract from $C$. album considerably decreased the rate of mycelium growth (data not shown).

The RP-HPLC-bound fraction of $P$. major completely inhibited germination of $S$. nodorum spores, but had no effect on other pathogens (Figures 3(a)-(e)). The antifungal activity in this plant was mainly associated with the RP-HPLCunbound fraction (Figures 3(a)-(e)). It completely inhibited spore germination in F. culmorum and $S$. nodorum and strongly suppressed this process in other tested fungi (Figures 3(a)-(e)).

It is interesting that incubation of $S$. nodorum spores with the RP-HPLCbound fractions from $C$. album and $P$. major led to disturbance of spore morphology (data not shown). In all probability, the inhibitory effect of these plant fractions on germination is due to loss of spore viability.

Both RP-HPLC fractions obtained from $E$. elongata strongly inhibited spore germination in A. alternata and B. sorokiniana (Figure 3(a) and Figure 3(b)) and caused $100 \%$ inhibition of spore germination in S. nodorum and two Fusarium species (Figures $3(\mathrm{c})-(\mathrm{e})$ ).

Plant fractions obtained by RP-HPLC of acid-soluble plant extracts displayed antifungal activity against $A$. alternata, $B$. sorokiniana, $F$. culmorum, $F$. oxysporum and $S$. nodorum. The latter was the most sensitive fungus to the extracts tested. Both bound and unbound RP-HPLC fractions of plants examined (except for $C$. album) completely inhibited germination of spores in this fungus. In the case of the RP-HPLC-bound fractions from $C$. album and $P$. major, this effect was associated with changes in spore morphology. Significant inhibition of $F$. culmorum spore germination was recorded with both RP-HPLC fractions from E. elongata and RP-HPLC-unbound fraction of P. major. F. oxysporum spore germination was also inhibited by the components of $C$. album present in the RP-HPLC-bound fraction. B. sorokiniana and A. alternata appeared to be less sensitive to plant extracts, however more than $75 \%$ inhibition of spore germination was achieved with both RP-HPLC fractions of $E$. elongata, the RP-HPLCunbound fraction of $P$. major and the bound fraction of $C$. album (against $B$. sorokiniana).

\section{Discussion}

Food-borne diseases caused by pathogenic microorganisms contaminating food products induce most gastrointestinal infections causing diarrhea, fever and other clinical manifestations. Pathogenic bacteria, such as Salmonella enteritidis, Escherichia coli, Listeria monocytogenes, Staphylococcus aureus, Campylobacter 
spp. are responsible for most of them. Over the last decades antibiotics traditionally used to cope with infections have become ineffective due to the emergence of pathogen resistance. Salmonella spp. became resistant to chloramphenicol and ampicillin. Methicillin-resistant $S$. aureus strains appeared. E. coli and related bacteria have developed resistance to third-generation cephalosporins. Enterobacteriaceae acquired resistance even to carbapenems. Resistance results from the global increase in antibiotic consumption and inappropriate use of antibiotics both in medicine to treat diseases and in agriculture to intensify food animal production. In addition to antibiotics, other chemical preservatives, such as chlorine dioxide and sodium nitrate in combination with physical preservation methods, such as freezing, thermal treatment, high hydrostatic pressure, pulsed electric fields are used in food industry to eliminate infection. Taking into consideration antibiotic resistance problem and consumer's demand for food safety the need for novel natural antimicrobials to eliminate food-borne pathogens is increasing. Plant diseases are another global problem. Pathogenic fungi dramatically decrease yields of cultivated crops and deteriorate quality of agricultural products. Fungicides, although effective, contaminate the environment and threaten human health. The search for novel ecologically friendly measures of crop protection is therefore necessary.

Plants represent a valuable but still insufficiently explored source of biologically active compounds that can serve, on the one side, as the basis for the development of novel pharmaceuticals for treatment of diseases and food preservation, on the other side, as novel plant disease control agents. Plant extracts represent enormous natural libraries of biologically active compounds that can be used for these purposes. Plants have been used for centuries in traditional medicine. Antimicrobial effect of plant essential oils and extracts has been successfully used in preservation of food products, pharmaceuticals and alternative medicine [19] [20] [21]. However, only 5\% - 15\% of existing plant species have been assayed for biologically active compounds. Substances that plants use to protect themselves from pathogens are structurally diverse. Secondary metabolites (phytoalexins and phytoanticipines) play an important role in plant defense strategy. They do not participate in key metabolic processes but are important for adaptation to stressful environmental factors and include compounds that protect plants from microorganisms, pests and other predators. These natural compounds can be used to control growth of pathogenic microorganisms in food products, either by inhibiting growth or killing them. Research in this field is in progress (see, for example [22] [23] [24]). Plant secondary metabolites fall into three main chemical classes: (1) phenolic compounds, the most abundant group of metabolites which protect plants from microbes, (2) terpenes and terpenoids, mono- and sesquiterpenes are important constituents of essential oils, (3) alkaloids. Not less important but much less studied group of plant components that can be used in medicine and agriculture are represented by polypeptide-based molecules. A special role in the development of novel drugs and crop protectants is occupied by endogenous antimicrobial peptides AMPs-effector 
molecules of innate immunity both in plants and animals that provide defense against a wide range of pathogens-bacteria, fungi and viruses. One of their most important advantages is that they do not promote resistance development in microorganisms.

In our work, we tested antimicrobial activity of several medicinal plants belonging to different families and widely spread in Russian Federation and former USSR: $C$. album, $P$. major, E. elongata, F. ulmaria, and $N$. sativa. The first three species are weeds, and all of them are edible plants, and thus safe for human health. To the best of our knowledge, before our study these plant species have not been examined simultaneously against important human bacterial pathogens (L. monocytogenes and E. coli) and plant fungal pathogens. To extract most completely biologically active compounds from these species, we have developed a stepwise extraction procedure including different types of solvents that allowed us to isolate both hydrophobic and hydrophilic seed components. For the first time, the RP-HPLC step was additionally included in the procedure to recover polypeptide-based molecules (RP-HPLC-bound fraction). We discovered that the antimicrobial activity of these seed extracts against $E$. coli O157:H7 and $L$. monocytogenes EGD-e was highly variable: from complete absence or low antibacterial activity (C. album) to strong inhibition by extracts from P. major, $E$. elongata and F. ulmaria (Table 1 and Table 2 ) with the highest activity observed in unbound fractions of acetic acid extracts. This fraction mainly contains hydrophilic non-protein components. The compounds present in the ethanol extract and in the RP-HPLC-bound fractions of the acetic acid extracts of all plant species did not display antibacterial activity. This indicates that ethanol-soluble components of seeds do not exhibit antibacterial activity, and that this activity is not associated with proteins. Seed extracts also differed in their ability to inhibit Gram-positive and Gram-negative bacteria. Both Gram-positive and Gramnegative bacteria were inhibited by the components present in RP-HPLC-unbound fractions of the extracts from P. major, E. elongata and F. ulmaria. N. sativa extracts suppressed growth of only Gram-positive $L$. monocytogenes, while hexane and ethyl acetate extracts of $F$. ulmaria and $P$. major were active only against E. coli.

Extracts from $F$. ulmaria exhibited the highest of all tested plants inhibitory activity against $E$. coli $\mathrm{O} 157: \mathrm{H} 7$. The hexane and ethyl acetate extracts as well as the RP-HPLC-unbound fraction of the acetic-acid-soluble extract suppressed growth of the bacterium. In the case of L. monocytogenes, only the RP-HPLCunbound fraction was active. It should be noted that the identified chemical constituents in F. ulmaria are salicylic acid, methyl salicylate, essential oils, flavone glycosides, flavonoids avicularin, quercetin and luteolin, and tannins [14]. Most of these components exhibit antibacterial/antifungal activity and may contribute to the antibacterial activity of the active extracts. We may suggest that essential oil components soluble in hexane are responsible for the antibacterial activity against $E$. coli. Essential oil constituents of a number of plants have been shown to display antibacterial activity. For example, carvacrol present in essen- 
tial oils of Origanum vulgare L. inhibits L. monocytogenes in vitro due to permealization of membranes [25]. We may suggest a similar mechanism for the hexane extract of F. ulmaria. Tannins also show antimicrobial activity, antilisterial, in particular, and they are present in $F$. ulmaria [5]. The antifungal activity of $F$. ulmaria resided mainly in the ethanol extract and RP-HPLC fractions. They caused complete inhibition of spore germination in all fungi and the oomycete $P$. infestans. The antifungal activity of RP-HPLC-unbound fraction is associated with hydrophilic seed components soluble in $0.1 \%$ TFA, while the activity of RP-HPLC-bound fraction, with polypeptide-based molecules. Ethanol-soluble biologically active compounds, presumably salicylic acid readily soluble in ethanol, are responsible for the potent antifungal activity of the ethanol extract of $F$. ulmaria seeds. These data are in accordance with literature data on inhibition of soil-borne bacterial and fungal pathogens with salicylic acid [26] [27].

$P$. major ethyl acetate extract and the RP-HPLC-unbound fraction were highly active against $E$. coli, while the hexane extract was moderately active. Only the RP-HPLC-unbound fraction was active against L. monocytogenes. This RPHPLC fraction was also highly active against the fungal pathogens. It completely inhibited spore germination in F. culmorum and $S$. nodorum. The RP-HPLCbound fraction was active only against $S$. nodorum. The biologically active compounds responsible for the antimicrobial activity of the extracts have not been identified. We may suggest that the biological activity of the RP-HPLCunbound fraction is mainly associated with water-soluble iridoid glycoside aucubin, although this plant species has many other valuable components with bactericidic and fungicidic activities, such as flavonoids, organic acids (benzoic, salicylic, citric), oxy-cinnamic acids (chlorogenic, ferulic, caffeic acid), saponins, and even alkaloids in small amounts [28] [29]. The antimicrobial activity of $P$. major extracts have been analyzed in a number of studies, and the antibacterial activity against some human pathogens was shown that is in accord with our results [30] [31] [32] [33] [34].

To the best of our knowledge, the antimicrobial properties of $E$. elongata have not been studied so far, and its chemical composition is unknown, however, its close relative E. repens contains carbohydrate triticin, flavonoid tricin, organic acids, volatile oil, consisting of agropyrene and monoterpenes carvacrol, carvone, thymol, menthol, menthone, and sesquiterpenes. The active substances of the aqueous extract are polysaccharides, flavonoids and tannins [35]. We discovered strong antibacterial activity of the RP-HPLC-unbound fraction of $E$. elongata against $E$. coli and L. monocytogenes and suppose that it may be associated with the antibiotic effect of agropyrene and some other mentioned-above compounds. Furthermore, both RP-HPLC fractions of the acetic acid extract of seeds displayed potent antifungal activity against tested plant pathogens: they completely inhibited spore germination in both Fusarium species and S. nodorum, and strongly suppressed this process in A. alternata and B. sorokiniana. We assume that the antifungal activity of the RP-HPLC-unbound fraction is due to agropyrene and other bioactive secondary metabolites, while that of RP-HPLC- 
bound fraction, with antimicrobial peptides. However, isolation and comprehensive structural and functional analysis of all active components is necessary to prove this suggestion.

$N$. sativa is called a miracle herb [17] because the seeds of this plant are widely used in treatment of various diseases. The therapeutic properties of $N$. sativa are associated with the presence of thymoquinone, which is the major component of essential oil [17]. Other active components of $N$. sativa seeds are thymohydroquinone, dithymoquinone, carvacrol, 4-terpineol, sesquiterpene longifolene, thymol and others. Seeds also contain two types of alkaloids-nigellicimine and nigellicimine- $\mathrm{N}$-oxide, as well as nigellidine and nigellicine. In addition to secondary metabolites, we demonstrated that $N$. sativa seeds contain two highly active antifungal peptides-defensins Ns-D1 and Ns-D2 [36]. In this work, we showed that seed extracts from $N$. sativa were inactive against Gram-negative $E$. coli $\mathrm{O} 157: \mathrm{H7}$, while potent inhibitory activity was shown for hexane and ethyl acetate extracts against Gram-positive L. monocytogenes. We suppose that this activity is associated with thymoquinone present in essential oil and extracted with hexane. Our results agree with those of other researchers. The antibacterial activity of $N$. sativa seeds against other Gram-positive bacteria, such as $S$. aureus, was reported [37]. The involvement of thymoquinone in bactericidal activity of $N$. sativa seeds against Gram-positive cocci $\mathcal{S}$. aureus and $S$. epidermitis was shown in a separate study with purified thymoquinone [38]. In our work, we also showed that the antifungal activity of $N$. sativa seeds against plant pathogens was mainly associated with the RP-HPLC-bound acetic-acid-soluble fraction, which contains polypeptide-based molecules. This fraction completely inhibited spore germination in P. infestans and B. sorokiniana after $24 \mathrm{~h}$ of incubation (Figure 2(a) and Figure 2(d)). We suppose that the antifungal activity of this fraction is due to highly potent defensins Ns-D1 and Ns-D2 [36]. Antifungal activity of $N$. sativa extracts was analyzed in a number of studies. The antifungal activity of aqueous extracts of $N$. sativa against Candida sp. was reported by Bita et al. [39]. The main components of $N$. sativa essential oil-thymoquinone and thymohydroquinone-were shown to possess strong antiyeast activity [40].

C. album was reported to possess a number of valuable compounds [41] [42], among them a novel phenolic glycoside named chenoalbuside isolated from the methanol extract of seeds [43], saponins [44], cinnamic acid amides [45], alkaloid chenoalbicin [46], phenols and lignans [47], free phenolic acids, gallic acid, caffeic acid, syringic acid and vanillin [48]. However, in our antibacterial tests against E. coli O157:H7 and L. monocytogenes EGD-e the extracts of $C$. album seeds showed no activity, except for weak activity (diameter of inhibition zone was less than $8 \mathrm{~mm}$ ) of the ethyl acetate extract against $L$. monocytogenes. Singh et al (2011) reported antibacterial activity of aqueous and methanol extracts of C. album leaves against several human pathogens including E. coli [49]. However in another study, methanolic and ethanolic extracts from leaves and flowers were inactive against selected bacterial strains [50]. Although inactive against human bacterial pathogens, the extracts from this species displayed potent anti- 
fungal activity. The RP-HPLC-bound fraction of the acetic acid extract completely inhibited spore germination in F. oxysporum and $S$. nodorum, and in $B$. sorokiniana germination was strongly inhibited by this fraction. The results on high antifungal activity of $C$. album extracts agree with those of Javaid A and Amin M (2009) who showed strong antifungal activity of the methanol inflorescence extract of $C$. album against Macrophomina phaseolina [51].

\section{Conclusion}

Different extracts from five medicinal edible plants widely spread in Russian Federation and former USSR were evaluated for antibacterial activity against two important bacterial food-borne pathogens ( $E$. coli and L. monocytogenes) and potent antimicrobial activity for four of them ( $P$. major, F. ulmaria, E. elongata, $N$. sativa) was shown. Furthermore, strong antifungal activity against six fungal and one oomycete pathogen of extracts from all plants was demonstrated. Further detailed analysis of biologically active fractions will form the basis for the development of environmentally safe natural products for medicine, food industry and agriculture.

\section{Acknowledgements}

The work was supported by Russian Science Foundation (grant no. 16-16-00032).

\section{References}

[1] World Health Organization (2014) World Health Statistics 2014. WHO, Geneva. http://www.who.int/gho/publications/world_health_statistics/2014/en/

[2] Slutsker, L., Evans, M.C. and Schuchat, A. (2000) Listeriosis. In: Scheld, W.M., Craig, W.A. and Hughes, J.M., Eds., Emerging Infections, ASM Press, Washington DC, 83-106.

[3] Vazquez-Boland, J.A., Kuhn, M., Berche, P., Chakraborty, T., Domínguez-Bernal, G., Goebel, W., González-Zorn, B., Wehland, J. and Kreft, J. (2001) Listeria Pathogenesis and Molecular Virulence Determinants. Clinical Microbiology Reviews, 14, 584-640. https://doi.org/10.1128/CMR.14.3.584-640.2001

[4] Farber, J.M. and Peterkin, P.I. (1991) Listeria monocytogenes a Food-Borne Pathogen. Microbiology Review, 55, 476-511.

[5] Paparella, A., Serio, A., Chaves Lopez, C. and Mazzarino, G. (2013) Plant-Based Intervention Strategies for Listeria monocytogenes Control in Foods. In: Mendez-Vilaz, A., Ed., Microbial Pathogens and Strategies for Combating Them: Science, Technology and Education, Formatex Research Center, Vol. 2, 1230-1246.

[6] Pushkareva, V.I., Didenko, L.V., Godova, G.V., Ovod, A.A., Kalashnikova, E.A. and Ermolaeva, S.A. (2013) Listera monocytogenes: Interactions with Agricultural Crops and Biofilm Formation Stages. Epidemiology and Preventive Vaccination, 1, 42-49. (In Russian)

[7] Izumiya, H. and Terajima, J. (1997) Molecular Typing of Enterohemorrhagic Escherichia coli O157:H7 Isolates in Japan by Using Pulsed-Field Gel Electrophoresis. Journal of Clinical Microbiology, 35, 1675-1680.

[8] Kaper, J.B., Nataro, J.P. and Mobley, H.L. (2004) Pathogenic Escherichia coli. Nature Review Microbiology, 2, 123-140. https://doi.org/10.1038/nrmicro818 
[9] Chen, H.D. and Frankel, G. (2005) Enteropathogenic Escherichia coli: Unraveling Pathogenesis. FEMS Microbiology Reviews, 29, 83-98.

[10] Cooley, M.D., Carychao, I. and Mandrell, R.E. (2008) Incidence and Tracking of Escherichia coli O157:H7 in a Watershed Associated with a Major Produce Production Region in California. PLoS ONE, 2, e1159. https://doi.org/10.1371/journal.pone.0001159

[11] Garmendia, J., Frankel, G. and Crepin, V.F. (2005) Enteropathogenic and Enterohemorrhagic Escherichia coli Infections: Translocation, Translocation, Translocation. Infection and Immunity, 73, 2573-2585. https://doi.org/10.1128/IAI.73.5.2573-2585.2005

[12] De Lucca, A.J. (2007) Harmful Fungi in Both Agriculture and Medicine. Revista Iberoamericana de Micologia, 24, 3-13.

[13] Mingazheva, A.M. (2012) Atlas of Medicinal Plants. Kitap, Ufa. (In Russian)

[14] Golovkin, B.N., Rudenskaya, R.N., Trofimova, I.A. and Shreter, A.I. (2002) Biologically Active Substances of Plant Origin. Vol. 3, Nauka, Moscow. (In Russian)

[15] Volynskii, B.V., Bender, K.I., Freidman, S.L., Bogoslavskaya, S.I., Glasyrina, G.A., Kaprelova, T.S., Koloskova, I.G., Kuznetsova, S.G., Martynov, L.A., Khlebnikov, A.N. and Khokhlova, D.S. (1988) Plants in Medicine. Saratov University Press, Saratov. (In Russian)

[16] Grieve, M. (1971) A Modern Herbal. Vol. 2, Dover Publications, New York.

[17] Ahmad, A., Husain, A., Mujeeb, M., Khan, S.A., Najmi, A.K., Siddique, N.A., Damahouri Z.A. and Anwar, F. (2013) A Review on Therapeutic Potential of Nigella sativa: A Miracle Herb. Asian Pacific Journal of Tropical Biomedicine, 3, 337-352.

[18] Balouiri, M., Sadiki, M. and Ibnsouda, S.K. (2016) Methods for in Vitro Evaluating Antimicrobial Activity: A Review. Journal of Pharmaceutical Analysis, 6, 71-79.

[19] Maedafkan, N., Iranmanesh, M., Larijani, K., Mahasti P., Nazari, F. and Zojaji, M. (2015) Chemical Components and Antibacterial Activities of Essential Oils Obtained from Iranian Local Lavandula officinalis and Thymus vulgaris against $\mathrm{Pa}$ thogenic Bacteria Isolated from Human. Journal of Food Biosciences and Technology, 5, 31-36.

[20] Rath, S. and Radhy, R.N. (2015) Antibacterial Efficacy of Five Medicinal Plants against Multidrug-Resistant Enteropathogenic Bacteria Infecting under-5 Hospitalized Children. Journal of Integrative Medicine, 13, 45-57.

[21] Witkowska, A.M., Hickey, D.K., Alonso-Gomes, M. and Wilkinson, M. (2013) Evaluation of Commercial Herb and Spice Extract against Selected Food-Borne Bacteria. Journal of Food Research, 2, 37-54. https://doi.org/10.5539/jfr.v2n4p37

[22] Pirbalouti, A.G., Chaleshtori, A.R., Tajbakhsh, E., Momtaz, H., Rahimi, E. and Shahin, F. (2009) Bioactivity of Medicinal Plant Extracts against Listeria monocytogenes Isolated from Food. Food, Agriculture and Environment, 7, 66-69.

[23] Kim, S.Y., Kang, D.H., Kim, J.K., Ha, Y.G., Hwang, J.Y., Kim, T. and Lee, S.H. (2011) Antimicrobial Activity of Plant Extracts against Salmonella typhimurium, Escherichia coli O157:H7, and Listeria monocytogenes on Fresh Lettuce. Journal of Food Science, 76, M41-M46. https://doi.org/10.1111/j.1750-3841.2010.01926.x

[24] Over, K.F., Hettiarachchy, N., Johnson, M.G. and Davis, B. (2009) Effect of Organic Acids and Plant Extracts on Escherichia coli O157:H7, Listeria monocytogenes, and Salmonella typhimurium in Broth Culture Model and Chicken Meat Systems. Journal of Food Science, 74, M515-M521. https://doi.org/10.1111/j.1750-3841.2009.01375

[25] Smith-Palmer, A., Stewart, J. and Fyfe, L. (1998) Antimicrobial of Plant Essential 
Oils and Essences against Five Important Food-Borne Pathogens. Letters in Applied Microbiology, 26, 118-122. https://doi.org/10.1046/j.1472-765X.1998.00303.x

[26] El-Mougy, N.S. (2002) In Vitro Studies on Antimicrobial Activity of Salicylic Acid and Acetylsalicylic Acid as Pesticidal Alternatives against Some Bacterial and Fungal Plant Pathogens. Egyptian Journal of Phytopathology, 30, 41-55.

[27] Amborabe, B.E., Fleurat-Lessard, P., Chollet, J.F. and Roblin, G. (2002) Antifungal Effects of Salicylic Acid and Other Benzoic Acid Derivatives towards Eutypa lata: Structure-Activity Relationship. Plant Physiology and Biochemistry, 40, 1051-1060.

[28] Samuelsen, A.B. (2000) The Traditional Uses, Chemical Constituents and Biological Activities of Plantago major L. A Review. Journal of Ethnopharmacology, 71, 1-21.

[29] Beara, I.N., Lesjak, M.M., Jovin, E.D., Balog, K.J., Anackov, G.T., Orcic, D.Z. and Mimica-Dukic, N.M. (2009) Plantain (Plantago L.) Species as Novel Sources of Flavonoid Antioxidants. Journal of Agricultural and Food Chemistry, 57, 9268-9273. https://doi.org/10.1021/jf902205m

[30] Saltan Çitoglu, G. and Atlantar, N. (2003) Antimicrobial Activity of Some Plants Used in Folk Medicine. Journal of the Faculty of Pharmacy of Ankara, 32, 159-163.

[31] Abd Razik, B.M., Hasan, H.A. and Murtadha, M.K. (2012) The Study of Antibacterial Activity of Plantago major and Ceratonia siliqua. The Iraqi Postgraduate Medical Journal, 11, 130-135.

[32] Sharma, H., Yunus, G.Y., Agrawal, R., Kalra, M., Verma, S. and Bhattar, S. (2016) Antifungal Efficacy of Three Medicinal Plants Glycyrrhiza glabra, Ficus religiosa, and Plantago Major against Oral Candida albicans. A Comparative Analysis. Indian Journal of Dental Research, 27, 433-436. https://doi.org/10.4103/0970-9290.191895

[33] Koohsari, H., Ghaemi, E.A., Sadegh Sheshpoli, M., Jahedi, M. and Zahiri, M. (2015) The Investigation of Antibacterial Activity of Selected Native Plants from North of Iran. Journal of Medicine and Life, 8, 38-42.

[34] Sharifa, A.A., Neoh, Y.L., Iswadi, M.I., Khairul, O., Abdul Halim, M., Jamaludin, M., Mohamed Azman, A.B. and Hing, H.L. (2008) Effects of Methanol, Ethanol and Aqueous Extract of Plantago major on Gram Positive Bacteria, Gram Negative Bacteria and Yeasts. Annals of Microscopy, 8, 42-44.

[35] Committee on Herbal Medicinal Products (2011) Assessment Report on Agropyron repens (L.) P. Beauv., Rhizomes. European Medicines Agency, EMA/HMPC/ 563395/2010. http://www.ema.europa.eu/ema/

[36] Rogozhin, E.A., Oshchepkova, Y.I., Odintsova, T.I., Khadeeva, N.V., Veshkurova, O.N., Egorov, T.A., Grishin, E.V. and Salikhov, S.I. (2011) Novel Antifungal Defensins from Nigella sativa L. Seeds. Plant Physiology and Biochemistry, 49, 131-137.

[37] Bakathir, H.A. and Abbas, N.A. (2011) Detection of the Antibacterial Effect of Nigella sativa Ground Seeds with Water. African Journal of Traditional, Complementary and Alternative Medicines, 8, 159-164. https://doi.org/10.4314/ajtcam.v8i2.63203

[38] Chaieb, K., Kouidhi, B., Jrah, H., Mahdouani, K. and Bakhrouf, A. (2011) Antibacterial Activity of Thymoquinone, an Active Principle of Nigella sativa and Its Potency to Prevent Bacterial Biofilm Formation. BMC Complementary and Alternative Medicine, 11, 29. https://doi.org/10.1186/1472-6882-11-29

[39] Bita, A., Rosu, A.F., Calina, D., Rosu, L., Zlatian, O., Dindere, C. and Simionescu, A. (2012) An Alternative Treatment for Candida Infections with Nigella sativa Extracts. European Journal of Hospital Pharmacy, 19, 162.

https://doi.org/10.1136/ejhpharm-2012-000074.203

[40] Halamova, K., Kokoska, L., Flesar, J., Sklenickova, O., Svobodova, B. and Marsik, P. 
(2010) In Vitro Antifungal Effect of Black Cumin Quinines against Dairy Spoilage Yeasts at Different Acidity Levels. Journal of Food Protection, 73, 2291-2295. https://doi.org/10.4315/0362-028X-73.12.2291

[41] Poonia, A. and Upadhayay, A. (2015) Chenopodium album Linn: Review of Nutritive Value and Biological Properties. Journal of Food Science and Technology, 52, 3977-3985. https://doi.org/10.1007/s13197-014-1553-X

[42] Sikarwar, I., Wanjari, M., Singh Baghel, S. and Vashishtha, P. (2013) A Review on Phytopharmacological Studies on Chenopodium album Linn. Indo American Journal of Pharmaceutical Research, 3, 3089-3098.

[43] Nahar, L. and Sarker, S.D. (2005) Chenoalbuside: An Antioxidant Phenolic Glycoside, from the Seeds of Chenopodium album L. (Chenopodiaceae). Brazilian Journal of Pharmacognosy, 15, 279-282. https://doi.org/10.1590/s0102-695x2005000400002

[44] Lavaud, C., Voutquenne, L., Bal, P. and Pouny, I. (2000) Saponins from Chenopodium album. Fitoterapia, 71, 338-340.

[45] Cutillo, F., D’Abrosca, B., DellaGreca, M., Di Marino, C.D., Golino, A., Previtera, L. and Zarrelli, A. (2003) Cinnamic Acid Amides from Chenopodium album: Effect on Seed Germination and Plant Growth. Phytochemistry, 64, 1381-1387.

[46] Cutillo, F., D’Abrosca, B., DellaGreca, M. and Zarrelli, A. (2004) Chenoalbicin, a Novel Cinnamic Acid Amide Alkaloid from Chenopodium album. Chemistry \& Biodiversity, 1, 1579-1583. https://doi.org/10.1002/cbdv.200490118

[47] Cutillo, F., DellaGreca, M., Gionti, M., Previtera, L. and Zarrelli, A. (2006) Phenols and Lignans from Chenopodium album. Phytochemical Analisis, 17, 344-349. https://doi.org/10.1002/pca.924

[48] Laghari, A.H., Memon, S., Nelofar, A., Khan, K.M. and Yasmin, A. (2011) Determination of Free Phenolic Acids and Antioxidant Activity of Methanolic Extracts Obtained from Fruits and Leaves of Chenopodium album. Food Chemistry, 126, 1850-1855.

[49] Singh, K.P., Dwevedi, A.K. and Dhakre, G. (2011) Evaluation of Antibacterial Activities of Chenopodium album L. International Journal of Applied Biology and Pharmaceutical Technology, 2, 398-401.

[50] Amjad, L. and Alizad, Z. (2012) Antibacterial Activity of the Chenopodium album Leaves and Flowers Extract. International Journal of Medical, Health, Biomedical, Bioengineering and Pharmaceutical Engineering, 6, 14-16.

[51] Javaid, A. and Amin, M. (2009) Antifungal Activity of Methanol and N-Hexane Extracts of Three Chenopodium Species against Macrophomina phaseolina. Natural Product Research, 23, 1120-1127. https://doi.org/10.1080/14786410802617433 
Submit or recommend next manuscript to SCIRP and we will provide best service for you:

Accepting pre-submission inquiries through Email, Facebook, LinkedIn, Twitter, etc. A wide selection of journals (inclusive of 9 subjects, more than 200 journals)

Providing 24-hour high-quality service

User-friendly online submission system

Fair and swift peer-review system

Efficient typesetting and proofreading procedure

Display of the result of downloads and visits, as well as the number of cited articles Maximum dissemination of your research work

Submit your manuscript at: http://papersubmission.scirp.org/

Or contact ajps@scirp.org 